\title{
ARQUETIPOS ESPACIALES Y ATMÓSFERAS EN AURA DE CARLOS FUENTES
}

\author{
Bruno Cruz Petit \\ Universidad Motolinía del Pedregal \\ Ciudad de México, México \\ investigacion@ump-mx
}

RESUMEN / ABSTRACT

\begin{abstract}
Este texto defiende una lectura de la novela Aura de Carlos Fuentes a partir del análisis de los espacios en los que transcurre la trama. La riqueza del texto proviene de la simultaneidad entre la descripción detallada de sensaciones físicas producidas por la casa de la calle Donceles y la carga simbólica del lugar. Interpreto la casa como un conjunto de atmósferas y arquetipos espaciales superpuestos, en cuyo núcleo es posible imaginar un teocalli prehispánico, dominado por una deidad que es Consuelo-Coatlicue, protagonista que puede ser leída como vehículo de mensajes poscoloniales, feministas y ecológicos.
\end{abstract}

Palabras clave: Espacio y literatura, arquetipos, atmósferas, Carlos Fuentes, Aura.

\section{SPATIAL ARQUETIPES AND ATMOSPHERES IN AURA BY CARLOS FUENTES}

Despite the abundance of critical literature on the novel Aura by Carlos Fuentes, the text defends the possibility of a new reading of the work with an analysis focused on the spaces in which the plot takes place as well as its internal structure. The underlying idea behind the work is that the richness of the text rests on the simultaneity between the detailed description of physical sensations and the fantasy unfolded (the spiritual arising from the material). Based on the study of sensations in the space described by the author, an interpretation of the house is proposed as a set of atmospheres and superimposed spatial archetypes, where the nucleus is capable to being perceived as a pre-Hispanic teocalli, dominated by a deity that is Consuelo-Coatlicue, an element charged with a meaning that is both feminist and ecological. KEYWORDS: space and literature, archetypes, atmospheres, Carlos Fuentes, Aura.

Recepción: 10/03/2020

Aprobación: 14/11/2020 
Toda obra que pervive en el tiempo, como Aura de Carlos Fuentes, va tomando significados distintos para diversas generaciones que ven reflejadas en ella sus inquietudes. Estas líneas proponen una prolongación de la interpretación en clave mítica defendida por Gloria Durán, profundizando sobre el papel del espacio en una escritura que, tras la apariencia de realista, busca conectarnos con elementos mágicos ancestrales (130). Si la narración puede verse como una reescritura de mitos del pasado, el espacio en el que tiene lugar también puede leerse en clave alegórica, como dispositivo que no solo da un ambiente adecuado a la trama, sino que apoya y estructura sus significados, los que, a su vez, cuestionan simbólicamente paradigmas de la modernidad, como el patriarcado o el progreso técnico, y que incluso permiten una lectura ecológica propia de nuestro tiempo.

La novela ha sido descrita a partir de su filiación con el cuento romántico de fantasmas (Silva 1; Albin 96; Eduave 4; López González 195), con la poesía barroca (Dhondt 80-90) y la literatura gótica (Nater 73-89). El estudio de Silva, en particular, da claves muy interesantes al señalar que, pese al recurso contemporáneo de la narración en segunda persona del singular al modo del nouveau roman, Fuentes "reduce la intensidad de la acción humana para favorecer la observación de un mundo en el cual predomina la materialidad de los objetos" (1). El autor pone una escritura realista a disposición de un relato fantástico; los objetos descritos visten espacios por donde circula una corporalidad (Felipe) que vive un rito de paso y un sacrificio. Silva ve claramente la importancia de la materialidad en la novela y señala una oposición entre un interior sagrado (donde las sensaciones son precisas, memorables) y un exterior profano-caótico (la calle ruidosa), distinción basada en Eliade y su teoría del espacio sagrado (28).

Si vemos la novela como perteneciente al gothic revival, tal como enfatiza Náter (75), el papel del espacio aparece como un elemento analítico fundamental. Sin duda, el género gótico está más ligado que otros estilos literarios a la espacialidad, ya que la creación de ambientes es esencial a la hora de transmitir la oculta presencia de secretos que revelan los oscuros y retorcidos pasillos de la mente humana. Así, no es casualidad que The Castle of Otranto (1764) de Horace Walpole, considerada la primera novela gótica, fuera obra de un escritor-arquitecto aficionado, creador de Strawberry Hill House, una de las primeras mansiones de inspiración medieval en Inglaterra. El género incluso admite que el escenario en ruinas de una abadía o una casa embrujada pueda convertirse en un elemento más importante que algunos de los personajes principales. Los fantasmas góticos y sus escondrijos reflejan una 
nueva actitud hacia la muerte, paralela a la secularización iniciada durante la Ilustración y la búsqueda de mundos alternativos, allá donde van los muertos (fantasmas) cuando no existe un paraíso o infierno. En este sentido, Lobell (69-73) sostiene que el recurso a "arquetipos espaciales" -la autora profundiza sobre la pirámide, pero podríamos añadir a su lista el castillo, el laberinto, la gruta, etcétera- sirve para movilizar elementos alojados en el inconsciente colectivo. Recordemos que, en un marco jungiano de análisis (Callan 65), los arquetipos, como formas de un orden psíquico a priori, forman un sustrato que adquiere consistencia empírica al ser vivido y expresado en cada cultura o individuo con elementos particulares. Muchas historias y ambientes de las novelas góticas pueden haber expresado y canalizado miedos y angustias de la sociedad victoriana, donde la seguridad burguesa no escapaba al peligro capitalista de caer en la insolvencia, la bancarrota, la ruina. La presencia de lo irracional y bárbaro, opuesto a lo civilizado (como elemento deseado y a la vez temido), la transgresión momentánea al orden social establecido y el espacio de la otredad, que contrasta con la calidez del home burgués y patriarcal (Davison 47-48), son recursos potentes y maleables que permitieron al gótico su reinvención y adaptación durante la modernidad, incluso en pleno siglo XX.

La interpretación de Náter (80) del libro como obra gótica coincide con las claves que dio el propio Carlos Fuentes ("On Reading" 536) sobre los orígenes de la nouvelle: el autor nos menciona a las brujas de Henry James, Charles Dickens y Aleksandr Pushkin. Náter aborda el tratamiento del espacio de la obra relacionándolo con la idea del espacio apocalíptico de la casa y el pueblo abandonado (Rulfo), paralela a la desintegración de los cuerpos y las mentes. La casa de Aura es, según este analista, un ambiente deteriorado en correspondencia con el cuerpo decrépito de la anciana Consuelo y la oscuridad del interior del edificio es correlato del oscurantismo y de la brujería. El análisis mítico que aquí defenderemos ve la casona de Consuelo, por el contrario, como un espacio con un orden interno, estructurado y estructurante, con claves interpretativas que no solo remiten a una brujería decadente sino a un espacio sagrado - en el sentido propuesto por Eliade y Silva- plenamente articulado.

$\mathrm{Al}$ dar protagonismo a la arquitectura de la casa y a su interior, el presente análisis se inscribe en la tradición de una crítica literaria interesada por el espacio como elemento que va más allá del papel de soporte o marco de la acción (Garrido Domínguez 207-211). Mencionemos aquí brevemente el creciente interés por el espacio en la crítica literaria en general (Slawinsky 
266-272). Este nos recuerda que, si bien los escritores clásicos y del medioevo manejaban escenarios, tendían a emplear fórmulas consabidas como el locus amoenus y centraban su interés sobre todo en las narraciones de los personajes y en la acción. A partir de la modernidad, el espacio aparece como un elemento protagónico (Spurr 3-6) que deviene clave para dar realismo a las novelas (Balzac), definir a los personajes -el espacio exterior como reflejo de la psicología interior- o como recurso para crear ambientes y dramatizar la acción (James), con escenarios sacados a menudo del gothic revival decimonónico.

En el siglo XX, en particular, la gran casa antigua, victoriana, historicista, va consolidándose como un arquetipo espacial con funciones similares a las que tenía el castillo en las novelas románticas del siglo anterior. Según Eligio García (238), la palabra "casa" aparece en numerosos títulos de la literatura de finales de los años cuarenta y cincuenta, lo que sugiere que el tema era una obsesión generacional. Julio Cortázar publicaría su cuento "Casa tomada" en 1946. William Faulkner publicó en 1959 La mansión, tras haber pensado y desechado como título La Casa oscura (The Dark House) para sus dos novelas precedentes. Este era un tema que interesaba no solo a novelistas y arquitectos sino también a los filósofos. En 1951, en Darmstadt, Martin Heidegger leía ante una audiencia de arquitectos alemanes su conferencia "Construir, habitar, pensar", en la que advertía sobre el peligro de pérdida de los valores existenciales de la habitabilidad en la arquitectura funcionalista de la reconstrucción durante la posguerra (162). El estilo que Jaime Alazraki (21-23) denomina neofantástico, al estudiar a Cortázar, recoge un anhelo por testimoniar un habitar auténtico en lugares significativos y sugerentes, lugares que en Europa y EE. UU. iban desapareciendo forzadamente a medida que avanzaba una modernización que los escritores latinoamericanos aún no habían vivido plenamente. En este sentido podríamos ver una equivalencia entre lo neofantástico de escritores como Fuentes, Donoso o Cortázar, y la literatura gótica europea del siglo XIX, una narrativa disidente en relación con la novela del progreso y del adelanto tecnológico. Se trata de una voluntad estética que tampoco era ajena a la crítica existencialista de la estandarización de la cotidianidad y la modernización tecnológica, siguiendo el antipositivismo del siglo anterior -desde el romanticismo al vitalismo, pasando por la fenomenología-, renovado por nuevas ideas en el ambiente existencialista de la posguerrera.

Al releer el texto de Carlos Fuentes, seguimos admirando su destreza en el lenguaje y su conocimiento literario, con claves intertextuales muy 
bien señaladas por los analistas. Lo que en una lectura moderna nos sigue sorprendiendo es, además, la minuciosidad con la que se describen los espacios, los objetos y las sensaciones. En Aura, Fuentes exhibe una extraordinaria capacidad para plasmar con palabras un espacio, por un lado, cargado de significado y, por otro, de atmósferas. Si recurrimos a lo que Tuna Ultav llama "análisis arquitectónico-literario" (134), una metodología de investigación de los textos literarios mediante descripciones de escenarios con conceptos a menudo propios de la arquitectura, entonces, es ineludible referirnos también a la categoría de "atmósfera", propuesta por el arquitecto suizo Peter Zumthor. En su libro Atmósferas, Zumthor afirma que, más allá del "pensamiento bello" hay una "magia de lo real" (18), de las relaciones directas entre las personas, cosas, espacios. Una atmósfera, para él, es el factor que provoca determinados sentimientos al entrar en un lugar. Particularmente, el proyectista suizo destaca el efecto producido por la consonancia de materiales, el sonido -el edificio como caja de resonancia instrumental, algo muy presente en Aura-, la temperatura, la luz, la arquitectura como entorno, la coherencia, el espacio como recipiente de cosas y la escala o grados de intimidad.

\section{SENSACIONES, RECORRIDOS}

La vivencia de Felipe Montero en la casa de Consuelo puede leerse como rito iniciático, un sacrificio, una exploración. Pero, en todo caso, si nos apegamos a la escritura, es también una vivencia fenomenológica de atmósferas, captadas por una corporalidad en movimiento que dibuja cinéticamente el espacio arquitectónico. El cruce de la puerta es un momento clave del texto, pues se trata del umbral, uno de los espacios más ambivalentes de la ficción gótica, que conecta y separa dos mundos -el conocido y el misterioso-y, por lo tanto, funciona como un límite y al mismo tiempo como una conexión:

Cierras el zaguán detrás de ti e intentas penetrar la oscuridad de ese callejón techado — patio, porque puedes oler el musgo, la humedad de las plantas, las raíces podridas, el perfume adormecedor y espeso-. Buscas en vano una luz que te guíe (Fuentes, Aura 6).

En una sola frase, el escritor abandona el ambiente urbano de las primeras páginas y se concentra en una minuciosa descripción de sensaciones olfativas que nos introducen en un entorno ambiguo: un patio con rasgos de jardín, la 
naturaleza en la propia ciudad. La luz es mínima, por lo que el joven visitante tiene que orientarse contando los escalones que una voz le ha indicado. La imposibilidad visual echa a andar toda la poética de la novela, obligando al protagonista y al lector a un ejercicio de imaginación auditiva y táctil. Diamela Eltit ha señalado que Aura es la novela de la penumbra (10), lo que es cierto sobre todo en el primer nivel, un patio-jardín que vamos viendo como un inframundo. Podríamos añadir que es la novela de una casa escuchada. La oscuridad del lugar impone un regreso a los sentidos considerados en Occidente más arcaicos y más relacionados con las emociones: el olfato, el tacto y el oído.

Del primer nivel de la casa solo vamos a conocer el patio -pudiera tratarse de un medio patio colonial, una vecindad, un jardín posteriormente construido-, al que regresará Felipe para descubrir las hierbas con las que la anciana elabora sus pócimas. El patio tiene una atmósfera muy particular, cargada de simbolismo - un inframundo o una alusión al descenso de Orfeo a los infiernos-. Durán (46-48), señala un antecedente de este jardín en el cuento de Fuentes "Tlactocatzine, del jardín de Flandes" (1952)-, donde la identidad real de la anciana protagonista está grabada en la inscripción de la puerta, "Charlotte Kaiserin von Mexico". El pasado europeo es ahí el elemento femenino que atrapa al héroe visitante. En Aura, por el contrario, se filtran elementos de un pasado prehispánico, anticipando un giro hacia constantes míticas más vernáculas en la obra de Fuentes, muy evidentes en las novelas Cambio de Piel y Zona Sagrada (Befumo y Calabrese 41-48), ambas publicadas en 1967.

La primera aparición de la señora de la casa es auditiva: "Le ruego. Camine trece pasos hacia el frente y encontrará la escalera a su derecha. Suba, por favor. Son veintidós escalones. Cuéntelos ahí" (Fuentes, Aura 6). Es una orden venida de un plano superior, el nivel en el que se encuentra un dormitorio dominado por el ambiente de las veladoras, colocadas de manera asimétrica, y "otras luces que son corazones de plata" (Fuentes, Aura 7). Solo tras franquear el velo de luz sagrada alcanzamos a ver, junto a Felipe, las manos de la anciana: "intermitente verás, al fondo, la cama y el signo de una mano que parece atraerte con su movimiento pausado" (ibid.). En el siguiente párrafo, las manos siguen siendo protagonistas: "al extender la mano no tocas otra mano, sino la piel gruesa, afieltrada, las orejas de ese objeto que roe con un silencio tenaz y te ofrece sus ojos rojos" (ibid.). La visión es ciertamente inquietante, ya no es una mano lo que se experimenta sino algo que roe, unos colmillos. Estos, junto a los corazones de plata 
mencionados y la visión inicial de las manos, pudieran estar evocando a Coatlicue, diosa madre de los mexicas también llamada Tonatzin, "nuestra madre", usualmente representada en bloque de piedra basáltico como anciana con los pechos enflaquecidos. La escultura de la diosa exhibida en el Museo Nacional de Antropología nos la muestra con un collar de manos y corazones humanos, que representan la vida, simbolizando la muerte sacrificial, y una falda de serpientes. Su cabeza está formada por dos serpientes encontradas que se encuentran. Al hablar de las inspiraciones de su obra, Fuentes cita no a Coatlicue sino a la diosa griega Circe, diosa que en La Odisea vivía en una mansión de piedra en medio de la isla de Eea y que con sus pócimas transformó a los marinos de Ulises en cerdos. Las coincidencias de ambos imaginarios pueden derivar aquí del papel del arquetipo universal de la diosa vengativa, la bruja.

Prosigamos en el análisis de los espacios que se han presentado al protagonista y al lector. Felipe ha subido y contado 22 escalones hasta la puerta de pino viejo del dormitorio. No sabemos qué forma tiene la escalera hasta ahí, ni qué hay en el primer nivel, quizás un rellano que da a la segunda puerta que le indica la propietaria tras su tropiezo. El texto da libertad a una evocación posible de la escalinata de una pirámide, donde el número de escalones era algo cargado de simbolismo. Tras la entrevista, Felipe Montero prosigue la ascensión a oscuras, más propia de la escalera de caracol de una torre del castillo que de una casa -“asciendes detrás del ruido, en medio de la oscuridad, sin acostumbrarte aún a las tinieblas" (Fuentes, Aura 13)hasta llegar al cuarto iluminado donde va a dormir: "al fin levantas los ojos hacia el tragaluz inmenso que hace las veces de techo" (ibid.). Este espacio corresponde a los aposentos del General Llorente, el lugar de lo masculino. El oculus del techo -aquel axis mundi o conexión de los distintos niveles cósmicos que Eliade menciona como propio del espacio sagrado (31)-da entrada a la luz (símbolo de la verdad); es el espacio de la revelación al final de la obra, cuando el protagonista ve a Aura en una foto histórica, junto al general, y comprende que ella es el doble reencarnado de la anciana.

Cuando Felipe, tras oír el sonido de una campana, regresa al nivel principal del inmueble para la cena, conocemos más acerca de la laberíntica sucesión de cuartos que dan al comedor en el que tomará sus alimentos. Es un nivel que conecta, por atmósfera y distribución, con arquetipos espaciales como la gruta, la caverna y el laberinto, y es la matriz de la casa, símbolo de la Tierra. Aparentemente, ese nivel central no tiene luz natural de ningún tipo, ya que los edificios colindantes modernos le hacen sombra -"nos amurallaron", relata 
Consuelo (Fuentes, Aura 20)-y las cortinas de la sala no dejan pasar la escasa luz de la calle. Del vestíbulo se pasa a una sala que contiene muebles forrados de seda mate, vitrinas con muñecos de porcelana, relojes musicales, cuadros, tapetes persas y cortinas verdes. El comedor es una habitación con muros recubiertos de madera oscura labrada al estilo neogótico, que se ilumina con el candelabro portado por Aura -personaje cuyo nombre sugiere el concepto de "aura" de Walter Benjamin, definida como "la presencia de una lejanía" (3)- también para trasladarse por la casa. Al comedor se llega pasando por una sala, la cual, adivinamos, es de poco uso y que tiene una puerta que da a una cocina. Allí Felipe lleva a cabo el rito de la cena: los riñones con cebolla y vino, claro símbolo eucarístico.

Si ya la recámara de Consuelo tenía un aspecto medieval con sus veladoras, la acumulación de objetos decimonónicos del comedor y las salas recuerda a los interiores descritos en el Libro de los Pasajes de Benjamin (38-45), quien muestra la arquitectura del siglo XIX con su vocabulario formal historicista, atmósferas oníricas y su énfasis en la interioridad, como una huida del racionalismo fabril y del caos urbano. En el vestíbulo, contiguo al dormitorio de la viuda del general, está la recámara de Aura, con una puerta que comunica interiormente ambas alcobas, lo cual da entender una continuidad entre los dos personajes. En la escena final del libro se menciona una rendija en el muro del cuarto de Consuelo, por la cual se filtra la luz de la luna. En esa luz tendrá lugar el último encuentro amoroso entre Felipe y Aura-Consuelo, que es plenamente una escena de sacrificio de la juventud ante la vejez y la muerte; una entrega a los dioses de lo más valioso, la vida en su plenitud del ser sacrificado, para asegurar la vida futura.

\section{ARQUETIPOS IMPLICADOS}

El análisis de los espacios de la novela nos ha confirmado la primera impresión que tuvimos al describir el contraste entre el mundo exterior del edificio y el interior: estamos dentro de un espacio sagrado, delimitado desde dentro por distintos subniveles simbólicos de distinto rango, que rompe con la idea euclidiana de espacio geométrico infinitamente divisible en partes homogéneas, así como el tiempo de la novela rompe con la noción de tiempo lineal -de ahí la coexistencia de varios estilos decorativos en el interior-y retoma la idea de reencarnación y eterno retorno. La articulación tripartita del espacio es paralela a la de la tríada arquetípica de los protagonistas (joven-anciana- 
doncella) presente, asimismo, en las novelas de James y Pushkin que anteceden a Fuentes. En dicha articulación, el escritor no dibuja un único arquetipo espacial, sino que, en su gusto por recuperar en el presente varias capas del pasado de México, acumula rasgos materiales de distintas épocas, que se van superponiendo los unos a los otros como ocurría con las distintas pirámides construidas sucesivamente sobre la original. La casa de Consuelo es una mansión vestida al estilo de Maximiliano, pero también una estructura que se erige sobre una edificación colonial, barroca, parcialmente desaparecida y relegada a una vecindad decadente. Una lectura atenta al recorrido del protagonista por la casa y a su simbolismo incluso nos anima a remontarnos en el tiempo y a ver, como núcleo generador, la estructura de un castillo gótico e incluso de una pirámide. En el esquema espacial que hemos descrito puede señalarse una sucesión interna de tres niveles del inmueble, que son también tres universos simbólicos distintos: un nivel de iniciación -el patio, la tierra del inframundo-, un segundo de sacrificio, y un nivel celeste de revelación. El segundo nivel nos remite claramente al imaginario del laberinto, pero también al del interior de los castillos - con su equivalente decimonónica, la mansión señorial- o al de las cuevas y grutas; es el útero de la casa, la parte visceral, donde se cubren las necesidades básicas de reproducción de la vida. La ascensión por una estructura triangular que tiene como base el patio y un vértice (las recámaras, que simbolizan el cielo) remite a la forma de una pirámide. Esta, a su vez, es la montaña mágica que conecta con el más allá o, según como queramos interpretarlo, la cúspide de una Torre de Babel donde el conocimiento no lleva más que a la hybris y al posterior sacrificio. La casa de Donceles ya no es unívocamente una reminiscencia de Chapultepec, como en "Tlactocatzine, del jardín de Flandes", sino una casa que da pie a múltiples interpretaciones.

La elevación vertical de la construcción marca un principio masculino que se opone y complementa con el laberinto terrenal que queda en el segundo nivel. Lo vertical dialoga con lo horizontal femenino. Como toda unidad, la casa de Consuelo-Circe-Coatlicue, diosas de la fertilidad y la tierra, contiene la dualidad. La casa representa la tierra que acoge y da, pero a costa del sacrificio; en este caso, el sacrificio de lo masculino - el marino de Homero es aquí Felipe-, en un rito que tiene lugar en el laberinto del segundo nivel -la última plataforma de la pirámide bajo las torres de los dioses-, tras el episodio de la epifanía en el último nivel. 


\section{EL PAPEL DE LA ATMÓSFERA}

El artículo del propio Fuentes titulado "On Reading and Writing Myself: How I Wrote Aura", inicia contando un suceso clave en la inspiración de la novela donde el espacio tiene un papel si no fundamental, definitivo. El escritor cuenta que la noche anterior a empezar la escritura de la novela, en el verano de 1961, se vio en su departamento del Boulevard Raspail con una chica de 22 años de edad, a la que no veía desde que ella tenía 14. Específicamente, el texto nos cuenta cómo al cruzar el umbral entre el pequeño salón y al entrar a la habitación donde Fuentes la esperaba, ella no solo era "otra" porque había pasado un tiempo y había crecido, sino que la luz de París, que entraba a las casas venciendo a la capa de neblina veraniega, "como perla encajada en una concha de nubes" con "una plenitud que también era agonía" (531), esculpía en el rostro de la joven el aspecto de la anciana que llegaría a ser: "Ese umbral entre el salón y el dormitorio se convirtieron en el dintel entre todas las edades de esta chica" (ibid.). La fusión de tiempos, en esta anécdota, es alimentada claramente por una atmósfera, una luz que penetra en un interior y se posa sobre una persona ubicada en un espacio de transición, el dintel de separación de dos recámaras. Esa transición permite el recorrido y la sorpresa del espectador (el escritor) que aún no participa de la escena, aunque está a punto de entrar en contacto con el visitante, con la que se sentirá, como Felipe, "en el reino del amor huésped extraño" (531). Ante tal visión, regresa a la mente de Fuentes el recuerdo de aquella tarde en la que Luis Buñuel, con el que tenía una conversación sobre el poeta barroco español Quevedo, se detuvo a mitad de camino entre el vestíbulo y el bar de su casa, y preguntó en voz alta: "Y si al cruzar el umbral de una puerta pudiéramos recuperar instantáneamente nuestra juventud; si pudiéramos ser viejos en uno, al lado de la puerta y joven tan pronto como la cruzamos ¿qué pasa entonces?" (532). La melancolía quevediana, la vida convertida en polvo, el sueño más real que lo real, que menciona Dhondt al interpretar Aura como una alegoría barroca (67), detona en esa conversación entre Buñuel y Fuentes una imagen surrealista donde la esperanza de vencer el paso del tiempo se condensa en el cruce de un umbral, la expresión de un mínimo recorrido con el máximo resultado. En Aura, la puerta de la casa de Consuelo en Donceles obra ese milagro, pero no en beneficio del que la cruza sino de su propietaria. De alguna manera, Fuentes, inconscientemente quizás, está sugiriendo que el secreto de la juventud eterna solo está en manos de la feminidad y que el hombre, en ese esquema, es una pieza que debe ser sacrificada. Esta es una 
novela sobre "una muerte disfrazada de vida", dijo el propio Carlos Fuentes ("Entrevista"), al contraponerla con el mensaje de la otra novela que escribía en esos mismos años: La muerte de Artemio Cruz, "una vida disfrazada de muerte" (ibid.). En Aura, la vida de la muerte es femenina; la muerte de la vida en Artemio Cruz, masculina.

Leslie Fiedler, al teorizar sobre las implicaciones del trasplante de la literatura gótica de suelo británico al americano sostiene que "de todas las ficciones del Oeste, nuestra propia [ficción americana] es la más profunda influenciada por el gótico, es casi esencialmente gótica" (129). Fiedler concibe la literatura gótica en la tradición americana como una forma masculina, caracterizada por la huida de lo femenino. El anti-home del espacio fantasmal es la voluntad de escape del mundo doméstico, una aventura masculina hacia lo ignoto. Asimismo, en Fuentes pudiera estar subyacente esta idea con un elemento masculino que, en este caso, no consigue huir, sino que es engullido por el femenino. Desarrollando esta interpretación, podríamos ver a Felipe como una alegoría del varón conquistador occidental, cuya modernización entraña la degradación de lo natural, y que, al entrar en el terreno de la diosa madre, la Coatlicue, queda atrapado por ella. Ante una Aura que encarna la orfandad parental mexicana -siguiendo la idea de Octavio Paz sobre el carácter del "macho" mexicano, "nada más natural, por tanto, que su indiferencia frente a la prole que engendra" (34)- la figura de Felipe actúa como el regreso del dios perdido, Quetzalcoatl (o Cortés confundido con el dios mexica), a una mexicanidad que prepara su venganza. La novela se puede entender como la historia de una revelación similar a la que tendrá el último Buendía al final de Cien años de soledad, al leer los papeles de Melquíades, que son la escritura de lo que ha vivido. En Aura se funden opuestos: el presente (Felipe) y el pasado (Consuelo). Cuando ocurre la unión de la dualidad-lo masculino y lo femenino- que los dos protagonistas encarnan, debiera desaparecer la vida, como en Macondo. En Aura, no obstante, no se acaba el mundo. En este sentido, Fuentes parece dejar inconclusa una historia que terminará García Márquez. Así, como reconoció el propio Fuentes, "todo libro prosigue a otros libros y anticipa otros libros" (cit. en Fortson 32). En realidad, los mensajes ocultos de la novela -el engaño de Consuelo al transmutarse en Aura, la muerte disfrazada de vida- proceden de una posible la venganza femenina (y poscolonial) por el abandono masculino. La mujer ultrajada que aparece en Paz como elemento de mexicanidad clave, toma aquí protagonismo. En este sentido, estamos ante una posible lectura ultramoderna y feminista del relato. Lectura a la que también se puede superponer una lectura ecológica, 
que conecta Aura con el lector del siglo XXI. La venganza femenina es una venganza de la Tierra (Circe-Coatlicue) ante la agresión de la modernidad. Es lo horizontal engullendo lo vertical, el laberinto natural triunfando ante la pirámide construida por los hombres.

\section{BIBLIOGRAFÍA}

Albin, María. "El fantasma de eros: Aura de Carlos Fuentes”. Atenea 494, 2006, pp. $127-$ 142 .

Alazraki, Jaime. “¿Qué es lo neofantástico?”. Teorías de lo fantástico. David Roas (ed.), Madrid, Arco Libros, 2001, pp. 265-282.

Befumo, Liliana y Elisa Calabrese. Nostalgia del futuro en la obra de Carlos Fuentes. Buenos Aires, Fernando García Cambeiro, 1974.

Benjamin, Walter. "La obra de arte en la época de su reproductibilidad técnica". Discursos Interrumpidos I. Taurus, Buenos Aires, 1989.

Libro de los pasajes. Madrid, Akal, 2005.

Callan, Richard J. “The Jungian Basis of Carlos Fuentes' Aura”. Kentuchy Romance Quaterly 18, 1971, pp. 65-75.

Davison, Carol Margaret. "Haunted House/Hauned Heroine: Female Gothic Closets in The YellowWallpaper”. Women's Studies 33, 2004, pp. 47-75.

DurÁn, GLORIA. "La magia y las brujas en la obra de Carlos Fuentes". UNAM. Opúsculos de la Facultad de Filosofia y Letras UNAM 85, 1976, pp. 242-245.

Dhondt, Reindert. "Lo barroco como sensibilidad: Aura". Carlos Fuentes y el pensamiento barroco. Madrid, Iberoamericana Vervuert, 2015.

Eliade, Mircea. Lo sagrado y lo profano. Paidós, Barcelona, 1998.

Eltit, Damiela. "La pasión según Aura”. Carlos Fuentes en el siglo XXI. Julio Ortega, Xalapa, México, Universidad Veracruzana, 2015, pp. 9-15.

Eudave, Cecilia. " Simbolismo y ritualidad en la novela Aura de Carlos Fuentes". Literaturas.com. (web), 2001, consultado el 21 de noviembre de 2021, disponible en: https://escrituracreativa. com/sin-categoria/aura-de-carlos-fuentes-proyeccion-ritual-y-simbolica-6994/

Forstson, J. R. Perspectivas mexicanas desde París: un diálogo con Carlos Fuentes. Ciudad de México, Corporación Editorial, 1973.

Fuentes, Carlos. Los días enmascarados. Ciudad de México, Los Presentes, 1954.

“Aura explicada por Carlos Fuentes 1977”. Entrevista con Soler Serrano (TVE, A fondo, 1977, YouTube (web), Arpantles, consultado el 21 de noviembre de 2021, disponible en: https://www.youtube.com/watch?v=PLRu8QTdtuI\&t=23s

"On Reading and Writing Myself: How I Wrote Aura". World Literature Today 57, $\mathrm{N}^{\circ} 4,1983$, pp. 531-539. 
Aura. Ciudad de México, Ediciones Era, 2001.

García Márquez, Eligio. Tras las claves de Melquíades. Bogotá, Norma, 2001.

Garrido Domínguez, Antonio. El texto narrativo. Madrid, Síntesis, 1993.

Heidegger, Martin. “Construir, habitar, pensar”. Teoría 6, º2, pp. 150-162.

Jung, CARL Gustav. Obra completa. Madrid, Editorial Trotta, 2011, pp. 155-158.

Llarena, Alicia. Espacio y literatura en Hispanoamérica. Culiacán, UAS, 2007.

Lobell, Mimi. “Spatial Archetypes”. Revision 6, N², 1983, pp. 69-82.

López González, Aralia. "Cuerpos y fantasmas del México en el imaginario de Carlos Fuentes”. Signos Literarios y Lingüísticos III, N², 2001, pp. 67-73.

NÁter, Miguel Ángel. "La imaginación enfermiza: La ciudad muerta y el gótico en Aura de Carlos Fuentes". Revista Chilena de Literatura 64, 2004, pp. 73-89.

Paz, Octavio. El laberinto de la soledad. Ciudad de México, FCE,1992.

Silva, María A. "El simbolismo erótico en Aura". Tesis, Documentos, Publicaciones y Recursos Educativos, Buenos Aires 1, 2003, pp. 1-10.

SLAwinsky, Janusz. "El espacio en la literatura: distinciones elementales y evidencias introductorias". Textos y contextos. Vol. II. Desiderio Navarro (comp. y trad.), La Habana, 1989, pp. 265-287.

SpurR, DAvid. Architecture and Modern Literature. Michigan, Ann Arbor-University of Michigan, 2012.

Tuna Ultav, Zeynep. et al. "Architectural literary analysis: Reading 'the death of the Street' through Ballard's literature and Trancik's lost space". Metu, Journal of the Faculty of Architecture 32, N², 2015, pp. 133-150.

Zumthor, Peter. Atmospheres. Basilea, Birkhauser, 2006. 